\author{
Adam Jagiello-Rusilowski \\ Uniwersytet Gdański \\ arusil@ug.edu.pl
}

\title{
Zhandarbek Immanchiyev
}

Abay Pedagogical University, Almaty (Kazahstan)

imanchiev_je@mail.ru

\section{Intercultural competencies of Polish and Kazakh teachers explored in their Facebook profiles}

\section{Summary \\ Intercultural competencies of Polish and Kazakh teachers explored in their Facebook profiles}

The aim of the study was to analyze Facebook profiles of teachers in Poland and Kazakhstan as the virtual educational space where intercultural competencies are manifested and further developed. The rationale for intercultural learning was derived from the pedagogies of Abay and Korczak while the list of attitudes, skills and knowledge to be observed was adapted from Deardorff's (2009) model. Digital ethnographic research approach was used for capturing teachers' behavior and artifacts in the field site. Teachers collaboration on a divergent problem and focus discussion afterwards provided further narrative material of reflective nature. The results suggest that Facebook profiles show ample evidence of competent intercultural behavior; they could be considered as e-portfolios and further researched for development of proper educational and validation tools for teacher training involving global networks.

Keywords: intercultural competences, Facebook, digital ethnography, teacher training, e-portolio

\section{The country cultural contexts}

Intercultural learning has become a dominant buzz notion in teacher training and development world-wide. While Higher Education institutions formally accept the need for structured courses and validation of intercultural competences, the instances of good practices dealing with the challenge are still rare. The more networked with mobility opportunities and information shared online learning becomes - the more it requires regulation skills and critical choices of inter-culturally competent individuals and teams (Brand-Gruwel 2009). Organizations thrive when their students or personnel are able to build their own culture, that is values, beliefs and norms held by the entire community which shape how individuals interact with each other and the rest of the world. Engaging the diversity of the cul- 
tures which students, faculty members or employees are willing to share and connect with needs both special instruction, but more importantly it has to be supported at the systemic grassroots level. The declared positive attitude of the faculty towards interaction with representatives of even distant cultures is not enough to model and train the new creative class capable of mobilizing untapped intercultural resources and collaborative problem solving. Social context, adequate instruction and feedback for students must at least be included in undergraduate education while intercultural learning which happens outside the campus should be validated by the Higher Education systems of quality assurance (Lee 2012).

The local socio-cultural contexts of Poland and Kazakhstan must be viewed as a challenge rather than opportunity for educational change towards engaging diversity from early learners to university graduates. Both mainstream communities value most social ties with family and close friends of similar backgrounds. Their "bonding social capital" is strong, but may hinder community development and innovation, when it is not augmented with "bridging capital" (willingness to cooperate with distant friends and workmates). Only then is the specific community able to build the most precious kind of social capital referred to as "linking". This in turn encompasses willingness to reach out to dissimilar people in dissimilar situations, those outside of the community, thus enabling members to mobilize a far wider range of resources than are available locally or within one nation/state (Woolcock 2001). Polish mainstream society and its culture are still not friendly enough for students and entrepreneurs with high motivation for "linking" diverse ideas with new resources. Environments based on trust, transparent law, and participatory inclusive social mechanisms are difficult to find in Poland not excluding its educational institutions (Czapinski 2009). In spite of dynamic socio-economic transformations Kazakhstan is still based on family or clan contracted culture and over $85 \%$ of the population mistrusts each other while $79 \%$ depends on the close ones for resources sharing and career development (Antfi 2010).

\section{Rationale and pedagogical authorities}

Poland and Kazakhstan both share tragic pasts of oppression by their neighbors which makes intercultural learning a very complex process and challenges teachers as agents of change. In their own education they could choose between the whole range of approaches to intercultural learning, but for the purpose of this article the two most inspirational figures for each country teachers will be analyzed: Abay and Korczak.

For Abay any cultural encounters had to be prepared by solid moral and ethical learning within the local values that is within folk creative activity and Islamic religious beliefs. This ethical basis stands beyond rational utilitarian-pragmatic knowledge, opposes assimilation, and dilution of the national spirit, including "avoiding the Russian sins" (Abay 1972). The aim of attachment to a distinct culture is to find genuine independence or sovereignty. Abay did not approve of "Kazakhs who sent their children to study in Russian schools to use their literacy as an advantage in their disputes with tribesmen". The most 
complicated and the most important issue of "intercultural enlightenment" according to Abay was to cultivate humanity ("Adam bo" - to be the first human). "Having learnt the language and culture of other nations, a person becomes equal among them, does not humiliate himself with useless requests"(Abay 1972). Deliverance from servility is achieved not via the acquisition of wealth or power, but via giving one's own personality the status of an equal subject in the development of the united world cultural space.

Abay's concept of the "conscientious mind" assumes that intercultural learning happens through dialogue which is not just an intellectual "search for the truth", but more importantly the faith-based enquiry appreciating human diversity resulting from gender, age, ethnicity, religion, social class and family history. The differences, oppositions and positions revealed through dialogue of Abay's conscientious mind" are not repressed but turned into a net of equal relationships, beyond hierarchy, selection or superiority: no single culture or national image of the world is superior to the others, so that the masculine essence ceases to dominate the feminine, the adult's over the child, the West over the East, Europe over Asia.

Korczak's concept for interculturally valid education was not derived from any specific ideological or philosophical perspectives, but was created as a tool to improve the learning environment in the interests of children. He understood that teachers can be the driving force for inclusive, intercultural education. Being a humanist, he believed in the uniqueness of each child and the particular historical, social, cultural, and political context of each setting. He also stressed that coercive authority or remote, impersonal theory cannot rule over a personal knowledge and understanding of human diversity which must be encouraged by educators through trustful relationships, modelling and inspiring readings. In his novel "Król Maciuś I" Korczak explored intercultural relations between different ages, social positions, ethnic differences to point to endless and powerful possibilities for mutual respect, understanding and appreciation, but this does not occur on its own without effort, dedication, patience, and education.

Every child who does not fit the general law must become a legitimate exception. In this case, too, what is needed is conscious, creative and devoted thought on the part of the teacher (Korczak 1914).

Korczak argued that the teacher should be an autonomous thinker and a lifelong inquirer into how exceptional learners are and how their diversity resulting from the complexity of their racial, social and cultural background may enrich the educator's competences and how it can contribute to the wisdom of the entire learning community. Korczak's revolutionary approach was to use the perspective of the children, including them in the process of designing their own education for a life full of dignity and fulfillment. He insisted that the teacher should respect a young learner as an actual person rather than as "a man to be, somebody of the future", the ultimate expert, a unique "research center" who can observe herself and others for 24 hours, feel, record and understand most of the emotions, access distant memories, create or recreate stories from her heritage (Korczak 1914). 
Korczak was also the precursor of drama as a tool for intercultural engagement of teachers and students in educational enquiry. He experimented with status, choosing real life dilemmas for the young learners and allowing them to speak from multiple perspectives, including the voices of authority they could have assumed. He noticed that the less exposed to intercultural interactions the children had been, the more they benefited from role and perspective taking, liberating themselves from limiting patterns of language and behavior.

\section{Competency model for evaluation}

While conceptualizing intercultural education can be derived for Polish and Kazakh teachers from the works of Korczak and Abay, the inquiry into their professional competences will be based on elements of the Finish model for developing and validating social competences as part of higher education learning outcomes (Jagiełło-Rusiłowski 2011). The essence of the model is its multi-perspective assessment of the individual as a member of a specific culture, the context of her/his intervention, the actual behavior (self-control and contribution to teamwork value adding) and the interplay of interest vested in the intervention. The assessing perspective must include at least the agent herself, peers, and a representative of an employer. The evidence of competency should come from actual intervention, narrative reflection on that intervention, as well as paper-and-pencil test results. E-portfolios have proved the most pragmatic form of evidence presentation so far in the European context of validating intercultural competences as networking social competences (Jagiełło-Rusiłowski 2012).

The effectiveness of intercultural interventions will be determined therefore by the individual while the appropriateness will only be evaluated by the other person - with appropriateness being directly related to cultural sensitivity and the adherence to the cultural norms of that person (Deardoff 2009). Based on recent intercultural studies the essential attitudes, knowledge and skills can be listed as the basic frame of reference for the research group of this report. Openness, curiosity, and discovery which imply a willingness to risk and to move beyond one's comfort zone while communicating respect to others, proved essential to demonstrate that others are valued. As attitudes they are fundamental to the further development of the knowledge and skills needed for intercultural competence. In regard to knowledge, cultural self-awareness (meaning the ways in which one's culture has influenced one's identity and worldview) must be prior to a culture-specific knowledge or deep understanding other world views, sociolinguistic awareness with understanding the reality from others' perspectives as the ultimate cognitive achievement. The skills that emerged from the studies included the acquisition and processing of knowledge: observation, interpretation and relating new elements to meaningful previous cognitive concepts.

These attitudes, knowledge, and skills ideally lead to flexibility, adaptability, an ethnorelative perspective and empathy. An ability to see from others' perspectives and to respond to them according to the way in which the other person desires to be treated may be 
reached by individuals in varying degrees of success and manifest in diverse forms. The summation of the attitudes, knowledge and skills, as well as the internal outcomes, is demonstrated through the behaviour and communication of the individual, which become the visible outcomes of intercultural competence experienced by others. Intercultural competence must be intentionally addressed in programs, orientations, experiences, and courses (Lee 2012). One may become inter-culturally competent in a variety of ways (readings, conferences, workshops and courses, everyday face-to-face as well as virtual interactions), but in order to achieve the full acquisition of competency, one must be immersed in the culture (Trimble 2009). Intercultural competence is a lifelong process - there is no one point at which an individual becomes completely inter-culturally competent. Thus, it is important to pay as much attention to the development process - of how one acquires the necessary knowledge, skills, and how one transforms his or her attitudes - as one does to the actual aspects of intercultural competence and as such, critical reflection becomes a powerful tool in the process of professional development. The overall elements can be visualized through the following model, thereby providing a framework to further guide efforts in developing and validating intercultural competence:

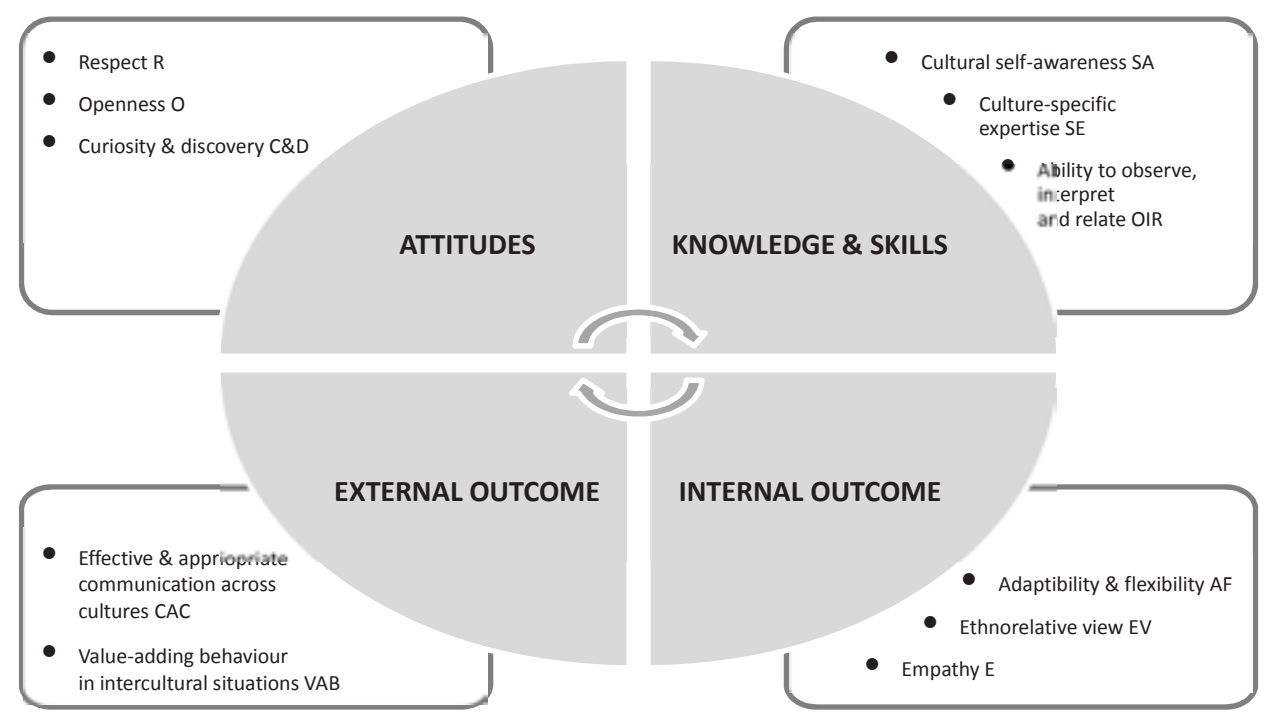

Fig. 1. Intercultural Competence Model (own representation and codes)

Source: D. Deardorff (2006), The Identification and Assessment of Intercultural Competence as a Student Outcome of Internationalization at Institutions of Higher Education in the United States. "Journal of Studies in International Education", fall 2006, 10, p. 241-266. 


\section{The study group and procedures}

The aim of the study was to analyze the Facebook profiles of teachers in Poland and Kazakhstan as the virtual educational space where intercultural competencies are manifested and further developed. The study adapted a digital ethnographic research approach combining observation and interviews on related content and behavior of selected teachers interacting with each other on Facebook. The researched group was made up of 20 in service teachers (10 from each country) from early (pre-school and elementary) to higher education ( $\mathrm{PhD}$ students or docents at affiliated universities), who accepted invitations from the authors of the study. The agreed system for sending the invitations was a previous involvement in educational programs mutually recognized as aiming at enhancing intercultural experiences. The common project was Odyssey of the Mind coaches' applied creativity training. In Poland the teachers had participated in drama-related seminars and projects (e.g. DICE, Wybrzeżak-Ciboly 2010). In Kazakhstan the invited teachers were involved in training and developing intercultural educational programs within the framework of a school subject called "self-knowledge" (Nysanbayev 2004). Additionally 6 Polish and 3 Kazakh teachers took part in an interactive part of the Stanford on-line "Creativity crush course" and shared their presentations with the remaining study participants through slideshare program. The task was a typical divergent problem for teamwork in which participants from distant locations had to brainstorm creative uses of different kinds of bread to promote intercultural learning.

The observation focused on the defined virtual world scope of fieldsite containing prospect evidence of inter-culturally competent interactions such as shared photos, invited friends, likes, posts, and chatlogs, shared video posts, and comments, networks and interest groups, time axis (last activities), places. The researched subjects accepted invitations as the researcher's friends making the observation process participatory and extended over the period of 2 months with the informed consent to access the published material, being prepared to reflect on their social site activities as well as the interactive project. After the observation period, including the time for the interactive project, a focus group discussion took place through Skype meeting facilitated by the authors.

\section{The results presentation}

Through an inductive analysis approach, the data from the Facebook fieldsite was coded and arranged into the following categories (with 1. as universal, 2. Polish-specific, 3. Kazakhstani) as elements of the intercultural competence model: 
Table 1. Evidence of intercultural competencies in Facebook profiles (collaborative summary)

\begin{tabular}{|c|c|c|c|}
\hline Fieldsite & Competences & Internal outcomes & External outcomes \\
\hline $\begin{array}{l}\text { Photos, } \\
\text { videos }\end{array}$ & $\begin{array}{l}\text { Profile photos feature } \\
\text { subjects } 1 \text {. against culture } \\
\text { specific background - CS } \\
\text { interethnic classes, study/ } \\
\text { action groups - C\&D } \\
\text { 3. in national costumes SA } \\
\text { Posted ones } 1 \text {. promote } \\
\text { human rights causes - R } \\
\text { 2. gender-equality - R,O. } \\
\text { 3. international trophies } \\
\text { - OIR }\end{array}$ & $\begin{array}{l}\text { 1. human suffering images } \\
\text { and video evidence - E } \\
\text { 2. minority identity, anti- } \\
\text { war posters - E 3. national } \\
\text { campaigns of religious } \\
\text { tolerance, multi-lingual } \\
\text { education - EV, AF }\end{array}$ & $\begin{array}{l}\text { 2. final intercultural project } \\
\text { presentations by students } \\
\text { - VAB } \\
\text { 3. blurred faces of subjects } \\
\text { sensitive to discrimination } \\
\text { or repression - CAC }\end{array}$ \\
\hline $\begin{array}{l}\text { Friends, } \\
\text { places }\end{array}$ & $\begin{array}{l}\text { 1. International, networked } \\
\text { via causes, interest or } \\
\text { alumni and teachers } \\
\text { (global) clubs - C\&D } \\
\text { 2. heritage, unique identity } \\
\text { - R, C\&D } \\
\text { 3. multilingual with large } \\
\text { networks, high status, } \\
\text { exclusive galleries versus } \\
\text { national monuments - SA }\end{array}$ & $\begin{array}{l}\text { 2. wide spectrum of } \\
\text { educational and social } \\
\text { backgrounds, travel or } \\
\text { foreign work contacts - AF } \\
\text { 3. orphanages, youth } \\
\text { prisons - E }\end{array}$ & $\begin{array}{l}\text { 2. membership and } \\
\text { rewards in problem solving } \\
\text { professional teams - VAB }\end{array}$ \\
\hline Likes & $\begin{array}{l}\text { 1. humor - SA, SE, } \\
\text { appreciating diversity - } \\
\text { R, global understanding } \\
\text { educational methods, best } \\
\text { practice sites - OIR } \\
\text { 3. images of status and } \\
\text { material success - SA }\end{array}$ & $\begin{array}{l}\text { 1. niche cultural/ } \\
\text { educational projects }-\mathrm{EV} \\
\text { 2. good (ethical) self-deeds } \\
\text { - E }\end{array}$ & $\begin{array}{l}\text { 2. conflict resolution, } \\
\text { engaging diversity } \\
\text { exchange programs - VAB }\end{array}$ \\
\hline Chatlogs & $\begin{array}{l}\text { 1. multilingual, resolution/ } \\
\text { task oriented, witty } \\
\text { exchanges - C\&D }\end{array}$ & $\begin{array}{l}\text { 1. exploring cultural } \\
\text { shocks, conflicts, } \\
\text { adaptation, stereotyping } \\
\text { and exclusion of/by } \\
\text { students - EV, AF, E } \\
\text { 3. challenging black or } \\
\text { white social judgments - } \\
\text { EV }\end{array}$ & $\begin{array}{l}\text { 1. negotiation of meaning } \\
\text { of respect in the context of } \\
\text { "Fred the Bred" exercise } \\
\text { - CAC } \\
\text { 2. respectful challenging of } \\
\text { gender equality - CAC }\end{array}$ \\
\hline $\begin{array}{l}\text { Time- } \\
\text { axis }\end{array}$ & $\begin{array}{l}\text { 1. invitations to key events, } \\
\text { intercultural conferences, } \\
\text { seminars, workshops, trip } \\
\text { check-ins - C\&D }\end{array}$ & $\begin{array}{l}\text { 3. inter-religion greetings } \\
\text { on students' profiles - EV }\end{array}$ & - \\
\hline
\end{tabular}


The most recurring evidence in the behavior of the observed group on their profiles was the empathic use of posted, shared with friends, or supported by like button multimedia material presenting human suffering in the context of armed conflicts (Middle East, Ukraine) and social exclusion. The most emotional reactions were evident when child abuse, forced labor or educational exclusion cases were featured on participants' profiles. Agents of violence were contested by Polish and Kazakh educators even when in some contexts their engagement (Gaza or Ukraine) could (and in two cases actually did as their profiles were temporarily blocked) impact their status at work. Some of the comments and the scale of sharing proved their genuine commitment to respecting or if necessary standing up for human and in particular child rights. The longest exchanges involving the research participants concerned cases of more local cases of educational exclusion of children "not fitting the general law" because of their handicap, family history, "rebellious" curiosity, or exceptional style of learning. Participants shared possible strategies that should have been used to replace the incompetent behavior of some colleagues with punitive tendencies. Websites openly pinpointing any discriminating practices by specific educational institutions or their employees were promoted by some Polish teachers while Kazakhstanis tended to ask valid questions (mainly to their colleagues) about strategies of challenging stereotyping and using methods of including minority students in meaningful projects enhancing their educational self-efficacy. Kazakhstanis expressed most concern on their profiles about the situation of socially excluded young people in prisons and the worrying mainstream attitude towards their fate enforced by the so called "svolotch" (Russian word for worthless mob) stereotyping. They took the opportunities of interacting with Polish and other international counterparts to attract more attention and allocating more resources to the problem of resocializing of that group as they noticed "doubly" oppressed by the Kazakh educational system. The problem was linked to early education pitfalls and underdeveloped methods of care given to orphans who in fact contribute to the volume and degenerated quality of the "svolotch" community in youth prisons. The teachers behavior on their Facebook profiles proves their intercultural competency twofold: they show empathy for the innocent young victims of social impotency (E), but also manifest their ethno-relative view attempting to diagnose the social mechanism that marginalizes certain ethnic and social groups by not addressing the problem at the early stages of education and not showing enough solidarity across the diverse cultures in Kazakhstan.

\section{Discussion of the results}

Inter-culturally competent teachers in Kazakhstan prove through their behavior on Facebook that by being empathic to the large group of youth labeled as "svolotch" they are also able to get to the core of the problem which may be rooted in the Kazakh culture which passes on quick social judgments and labels. It requires some flexibility and distancing to notice that seeing complex social mechanism in black or white categories leads to serious systemic traps. It takes some civil courage to re-define the functions of early educa- 
tion and competencies of the teachers in pre-school and elementary school to prevent the high rate of school drop outs among the more disadvantaged children regardless of their ethnic or religious background. While tolerance to the diversity of religion, nationality, language, and obedience to ethnic traditions and codes are taken for granted the intercultural competence of educators manifests itself in their, as Abay postulated, "faith based inquiry" into what actually causes the pre-mature educational exclusion of certain Kazakhstanis. Although posting greetings on students' Facebook profiles on their specific religious holidays proves teachers' ethno-relative views more focus is given to the category of external learning outcome which includes the ability to solve intercultural problems in a creative way to create necessary social change. Again the intercultural competence of Kazakh teachers is twofold here. It requires their cultural self-knowledge, but also ability to outsource the possible solutions and work in international teams on educational change to include the "svolotch" into the mainstream schooling benefits.

Apparently contrasting, but in fact perfectly consistent with the other evidence of both Kazakh and Polish teachers' intercultural competency, was their specific use of humour. It was manifested in all the observed fieldsites from profile photos to travel places entries on their time axis. The "likes" they distributed among Facebook friends, posts or events clearly promoted strong sense of humor even when the content or social message itself was serious, related to issues of global peace, human rights, important educational research etc. Appreciating humor was as characteristic of their behavior as recognizing specific people and organizations for generating intercultural solutions to existing global problems. The researcher group had contrasting networks of friends, either large or very small, but heavily connected and active. In all cases, however, the friends came from more than the host country and used several languages with English or/and Russian as lingua franca. The choice of contacts appears to be based on shared values of tolerance, love of peace, and curiosity about how problems are defined and solved in different cultural contexts. Both Polish and Kazakh teachers clearly avoided comments on their profiles potentially triggering any display of hostility towards representatives of a specific nationality, other culture, or religion. During the observation period they never used hatred speech themselves, while they often stood up against cases of violence, prejudice, discrimination via causes or peace campaigns. They stayed away from emotional exchanges on current political issues or religious conflicts. The strongest evidence of their competency came when one of the Polish participants shared what she believed was a funny scene from the film "Borat" by Sasha Baron Cohen. Kazakhstanis find the whole project extremely offensive to their nation and culture and once that expertise was communicated among the Polish network apologies were accepted and the sense of humor of Kazakhstanis was not challenged. The most sensitive issue of gender stereotypes and prostitution in Kazakhstan was discussed in the context of educational law rather than the fiction. As in case of other contributions to lengthy, in some cases multilingual, chats, that discussion as well was task oriented, expressed (sometimes bilingually) as divergent questions rather than strong opinions or final judgments. Both Poles and Kazakhstanis initiated and moderated original 
discussions with ad hoc links, photos or alternative non-fiction videos aimed at broadening the collective knowledge, perspectives, and cultural awareness on gender inequalities.

When asked in the focus group discussion why they created and maintained their profiles on Facebook, the informants from both countries stressed the need to stay in touch with people who can be inspiring, and share information and professional advice. They also reported the willingness to connect with international colleagues of strong ethical fiber and a strong sense of humor at the same time. While Polish teachers emphasized their expectations of Facebook to be the platform for meeting other educators as critical thinkers rather than conformists who seek popularity among the biggest possible audience, Kazakhstanis admitted the cultural difference here. Some of their networks had over 5000 friends (with some fake identities bought on sale in Turkey) and were openly intended to impress others as sign of high social status or threat of exerting pressure on those who dare to challenge that status.

The focus group discussion was devoted to exploring revealed cultural difference as some Polish teachers experienced real cognitive dissonance after honest exchanges with their Kazakh counterparts. Participants from Poland assumed that what they should be sharing on Facebook are highly ethical examples of their behavior like Iwona's (43) story:

The wallet I found in Riviera Mall had more cash that my monthly salary. And what did the good old teacher (belfer) do? There were not even second thoughts... You may call me conformist or old fashioned but I would stop regarding myself as an educator if I did not take the wallet to the police and get satisfaction from the gratitude of the women who had lost the wallet.

Kazakhstnis responded that showing off with the large number of (fake in some cases) friends and posting pictures of exclusive shopping malls has nothing to do with deceiving anybody. It is just a way of making up for years of cultural oppression (by Soviets), poverty and isolation and maybe a lame way of organizing a positive community. Gulnasyl (32) commented:

It will soon pass and we will do more of spiritual talk over Facebook addressing each other like nobody in the world. We are sending a lot of such messages already. In the meantime, however, you cannot find your poor neighbors on Facebook can you? You have plenty, though who will be happy to join you because you seem like them. One day you may help the poor to organize something through Facebook... The network even if not so big in reality is still more powerful than one idealistic under-paid Kazakh educator.

Declarations of this sort should be considered as further evidence of intercultural learning rather than hypocrisy. They stand in clear contrast to the general aims of average virtual social network users. Users joining social networking sites, such as Facebook, first conform to social phenomena by joining an already heavily used site, and further conform to societal and group pressures as they operate profiles and target specific audiences with communications. If we understand the notion of identity on Facebook as dynamic tension 
between how users define themselves as individuals and how they connect to their contacts and other online communities, in affiliative relationships we can expect the users to employ a degree of conformity to generate understanding and become recognized by their intended audience or social group.

The observed teachers explain their non-conformist behaviors on Facebook during the group focus discussion by declaring flexibility allowing them to see the traps which the need to be accepted by friends can set up for their further development. They attribute their choices of photos, posts, and the timing of their presence on social networks to the drive for getting the feedback from other international expert teachers, teaming up for any intercultural project opportunities rather than just standing out on Facebook for its own sake. They find Facebook useful for satisfying their curiosity and discovering how different people live and solve problems, how their own cultures inspire them to dress, eat, study, worship but, above all strategize. Facebook, however distorted, still is the most accessible way for them to observe, interpret, and relate distant cultural wisdoms to their everyday learning and dilemmas. A Kazakh informant (Sattar 23) declares:

I don't go to Facebook to give "likes" to celebrities or play games suggested by ads. I am interested to know how real people function in Europe, US or Japan, what is important for them, what stresses them, and what they would do if they had to live in my place.

Another young teacher from Poland (Luke) admits he gets on Facebook almost in real time if something urgent is happening globally:

When I get notifications from Causes I feel responsible for checking them and pass on to friends. I know that if there is a large group of Facebook users supporting a protest against violence or discrimination happening somewhere far - the offenders will be warned about it. It may be a big word, but I believe in this kind of solidarity.

Facebook users are aware that having the right network can improve their social standing and provide access to new opportunities. On the other hand, the image and reputation they build in this way may suffer when people with whom they are associated (offenders) act in socially inappropriate ways. In this case being associated with negative Facebook users can be detrimental to one's social capital gathered both through online as well offline interactions. As networks are extremely visible on Facebook, many users demonstrate discretion in the contacts they add to their profiles to reduce the risk of negative image. Intercultural competence is something vital in navigating your Facebook contacts in such a way that it serves you and your network. None of the observed teachers ever un-friended anybody, but they had been critical in whom they invited so they could rely on those relationships for support, but also collaborate in difficult times. The concept of making a social impact in one's network was a theme revealed among most research participants. They get on Facebook to employ their influence, ignite their curiosity, and seek adventure 
as they communicate and learn from their friends and colleagues. In what they perceive as intercultural learning experience teachers see the extension of their professional training.

The Stanford on-line creativity challenge was a good example for them of what opportunities Facebook gives for professional life-long learning. Brainstorming the alternative uses of bread across cultures and geographical distances revealed some competencies, deficiencies, and need for further education in the field. Cultural sensitivity or ethno-relative view was not enough to navigate through such challenges like negotiating the time for virtual meetings or team roles in the context of creative problem solving. During the group focus discussion it turned out that the problem offered by the Stanford scholar was in a way culturally biased as it assumed Western concepts of problem solving by teams with clearly defined roles (e.g. De Bono's thinking hats). The participants seemed to get into traps of power struggle to lead the process or author the solutions. Kazakhstanis found the experience somehow reflected the Eurocentric view of intercultural learning where such assumptions like English as a working language or GMT as time for virtual meetings are taken for granted by partners further East. In the end. However, the experience was welcomed both by Kazakh and Polish participants and praised as an opportunity for intercultural insights. It was welcomed by educators as a rare opportunity to exercise generation of value-added solutions which otherwise do not naturally occur on Facebook.

\section{Conclusion}

The study reveal much meaningful evidence of the intercultural competencies of the teachers who show strong identification with educational programs derived from the pedagogies based on the ideals of Abay in the Kazakh and Korczak in Polish contexts. Facebook profiles reveal their openness, curiosity, and discovery. Their posts and commitments to noteworthy networks manifest willingness to risk and to move beyond one's comfort zone while communicating respect to members of other cultures. They demonstrate their own cultural self-awareness as well as culture-specific knowledge or deep understanding of other world views, sociolinguistic awareness, with understanding the reality from others' perspectives. The observed teachers appear to be sensitive to pitfalls of the educational systems in both countries which are at the root of harming, labeling, stereotyping and inequalities which in consequence exclude large populations from social support systems or even sentence them to the horrors of imprisonment. Their intercultural competences are called for especially at the early stages of education, especially in Kazakhstan where ethnicity, poverty, or dysfunctionality of family may result in exclusion.

The limitation of the study is not just a research group which is far from being representative of both populations in any way or the netnographic method which focuses on meanings attributed to the listed components by the study participants rather than the actual level of the intercultural competencies in question. The study merely explored the possibilities of intercultural competencies as revealed in virtual spaces. The observed teachers did not undergo any specific programs designed to produce learning outcomes. 
The study therefore did not aim at assessing such outcomes. It just pointed at Facebook as an interesting space for both learning and recording the evidence of intercultural competencies. In the absence of more rigorous research projects involving the use of Facebook or e-portfolios as a way of developing and validating intercultural competencies, it could be considered by diverse stakeholders of teacher vocational training as trend setting and opening up possibilities of further scrutiny of virtual social network spaces as platform for intercultural learning.

\section{References}

Abay. The Book of Words // Shakarim. The Notes of Forgotten. Almaty, Zhazyshi, 1992.

Antfi B.F. (2010), What does a comparison between Latvia, Lithuania, Kazakhstan, and Kyrgyzstan tell about the cognition and institutions as social capital in the extended market order? Online at http://mpra.ub.uni-muenchen.de/22835/MPRA Paper No. 22835, posted 21. May 2010 19:33 UTC.

Brand-Gruwel S., Woperais I., \& Walraven A. (2009), A descriptive model of information problem solving while using internet, "Computers \& Education", Vol. 53, No. 4.

Ciboly A., Jagiello-Rusilowski A. (2010), DICE consortium white paper, available at www.dramanetwork.eu

Czapiński J. (2009), Kapitat społeczny. W: J. Czapiński, T. Panek (red.), Diagnoza Społeczna 2009. Warunki i jakość życia Polaków. Warszawa, Rada Monitoringu Społecznego, Wyższa Szkoła Finansów i Zarządzania w Warszawie.

Jagiełł-Rusiłowski A. (2011), Fiński model kształcenia i walidacji kompetencji społecznych. Warszawa, IBE.

Jagiello-Rusilowski A., Pentilla T., Karisto-Metanen L. (2012), Validating Innovation Competences as Learning Outcomes, Engineering Education (ICEE) 25.

Korczak J. (1967), How to love a child (J. Bachrach, Trans.). In: M. Wolins (Ed.), Selected works of Janusz Korczak. Washington, DC, National Science Foundation. (Original work published in 1914).

Lee A., Poch R., Williams R. D., \& Shaw M. (2012), Engaging diversity in undergraduate classrooms: A pedagogy for developing intercultural competence. Association for the Study of Higher Education Series. San Francisco, CA, Jossey-Bass.

Nysanbayev A. (2004), Kazakhstan - cultural inheritance and social transformations. In: G. F. McLean (Ed.), Cultural Heritage and Contemporary Change Vol.2. Washington.

Trimble J. E., Pedersen P. B., \& Rodela E. S. (2009), The real cost of intercultural incompetence. In: D. Deardoff (Ed.), The Sage Handbook of Intercultural Competence. Los Angeles, CA, Sage.

Woolcock M. (2001), The place of social capital in understanding social and economic outcomes. "Canadian Journal of Policy Research" 2(1). 